\title{
Peertechz
}

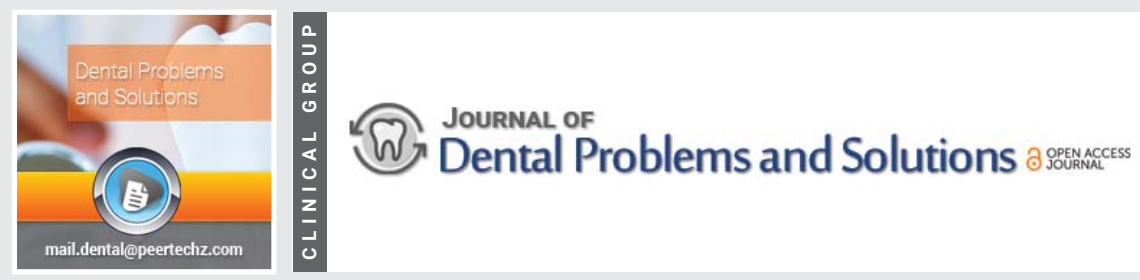

\section{How the myobrace appliance works: Advantages and disadvantages}

\section{Paola da Cunha Busquet ${ }^{1 \#, ~ D e s i r e ́ e ~ d e ~ J e s u s ~ P o r t e l i n h a 2 " ~}{ }^{2}$, Monica Lage da Costa ${ }^{1 *}$ and Viviane de Andrade Cancio de Paula ${ }^{2 \star}$}

1Salgado de Oliveira University, School of Dentistry, Rua Marechal Deodoro 217, Centro, Niterói, RJ, CEP 24040-110, Brazil

2Department of Pediatric Dentistry, School of Dentistry, Fluminense Federal University, Rua Mário

Santos Braga, no 30-Campus Valonguinho, Centro, Niterói, RJ, CEP 24040-110, Brazil

\#All authors contributed extensively to the work presented in this Manuscript
Accepted: 18 March, 2021

Published: 19 March, 2021

*Corresponding author: Dr. Viviane Andrade Cancio de Paula-Universidade Federal Fluminense/Faculdade de Odontologia, Rua Mário Santos Braga, no 30-Campus Valonguinho, Centro, Niterói, RJ, CEP 24040-110; Ph: 5521 2629-9829; Brazil, E-mail: vicancio@ig.com. br; odonto.cancio@gmail.com

Keywords: Facial muscles; Myofunctional therapy; Orthodontics, Children

https://www.peertechzpublications.com

\section{Check for updates}

\section{Abstract}

Myofunctional Dentistry is a treatment that acts in the re-education of facial and masticatory muscles, correcting bad myofunctional habits such as mouth breathing, atypical swallowing and incorrect tongue positioning, directs the growth and correct development of the cranio-cervical-mandibular complex structures and helps in alignment and leveling of teeth in patients of all ages. Myobrace is a myofunctional device of Australian technology that promotes the correction of habits and dental alignment without the use of brackets. The objective of the work was to present a literature review of the Myobrace device. To this end, a survey was carried out in research bases (Medline, Cochrane, Embase, Pubmed, Lilacs and BBO) between the years 2019 and 2020, focusing on randomized clinical studies, prospective nonrandomized longitudinal studies, systematic and meta-reviews analyzes, clinical cases that used Myobrace. As a result, after applying the inclusion and exclusion criteria, articles were found, which were used to carry out this work. It is concluded that orthodontic treatment cannot be considered a contributing factor for the development of temporomandibular disorders.

\section{Introduction}

The movement called Myofunctional Orthodontics attracts dentists' attention to the origin of malocclusions, such as artificial breastfeeding, pacifiers, mouth breathing and its consequences on children's development. The chances of relapse become greater when the factors causing malocclusions are not treated orthodontically $[1,2]$.

The function of respiration is inserted in a larger organic complex called the stomatognathic system that is composed of static structures, which comprise the maxilla, the mandible, the temporomandibular joint, hyoid bone and cranial bones, and of dynamic structures that comprise those that move the static parts. All of these structures work together, under the control of the central nervous system, performing the functions of breathing, speech, sucking, chewing and swallowing [3].
Several factors can cause oral breathing, such as anatomical, inflammatory, genetic and also infections. However, the hypotheses in which the individual breathes through the mouth due to habits acquired over time, without any real impediment in the upper airways, may be called myofunctional habits [4].

The correction of myofunctional habits such as atypical swallowing, lingual interposition, mouth breathing, simultaneously with dental alignment is the objective for which functional appliances have been gaining space in current Dentistry. Bracket devices are the main ones used by orthodontics, however, one of its main disadvantages is relapse in many cases [5].

The Myobrace system offers an alternative method for the use of brackets that presents the most stable results, as it treats one of the main causes of recurrences, which are myofunctional habits. There are several prefabricated positioners made of 
different materials, some rigid and with good resistance, but with less comfort for the patient, others more flexible, soft and comfortable, but with low resistance, Myobrace simplifies orthodontics, because it unites all these functions [6].

Based on the context, the objective of the work was to present a literature review of the Myobrace device, presenting the ways of operation, treatment options and its advantages and disadvantages.

\section{Literature review}

A search was carried out Medline, Cochrane, Embase, Pubmed, Lilacs and BBO databases, in the period from2019 to 2020. Research descriptorsused were "Facial Muscles", "Myofunctional Therapy", "Orthodontics", "children",which were crossed in the search engines. The initial list of articles was submitted for analysis by two evaluators, who applied inclusion criteria to determine the final sample of articles, which were evaluated by their title and abstract. If there was any discrepancy between the results of the evaluators, a third evaluator was consulted by reading the full version of the article.

The following inclusion criteria were used for the selection of articles: »Case studies with myobrace » Randomized clinical studies, prospective non-randomized longitudinal clinical studies, systematic reviews and meta-analyzes, and clinical studies should presente group control »Clinical studies where examination was performed clinical-physical in patients, and at least clinical evaluation has been carried out after completion of treatment »Studies written in English, Spanish and Portuguese, and published between the years 2019 and 2020. Thus, cross-sectional studies, authors' opinions were excluded, as well as studies where the treatment had not yet been concluded and studies based only on imaging exams.

Breathing influences the maintenance of skeletal, dental and muscular organization of the stomatognathic system, thus contributing to the adequate development of orofacial functions and harmonious skeletal growth. All bone growth occurs through the basic mechanisms of remodeling, sliding and displacement, as is the example of the maxillary growth $[4,7]$.

When the individual's morphology is adequate, the normality of the structures generates conditions favorable to the balance of the stomatognathic system. In the presence of changes, orofacial myofunctional disorder arises, which alters the normal pattern of chewing, swallowing and speech functions [8]. In the presence of orofacial myofunctional disorders, the stomatognathic system, even with changes, continues to function to perform its vital functions [9].

The mouth breather has dentofacial changes, and this occurs as a result of inadequate muscle pressures on the skull bone structure. In normal breathing, air enters through the nose allowing its purification, filtration, heating and humidification. Meanwhile, the tongue is positioned on the palate, touching the tip to the incisal papilla. When breathing through the mouth, the tongue is positioned improperly on the oral floor, and this position is responsible for dental and skeletal changes $[4,10]$.

The deleterious habits, abnormal and habitual patterns of muscle contraction that can interfere with craniofacial growth and the performance of these functions can be classified into: non-nutritive sucking (pacifier sucking, digital sucking); nutritive sucking (prolonged use of a bottle); biting habits (objects, onychophagy and bruxism) and functional habits (oral breathing, atypical swallowing and speech disorders) [11]. Among the consequences associated with these habits, the following stand out: changes in the morphology of the hard palate, dental malocclusions, changes in tone and mobility of the tongue, lips and all perioral and phonoarticulatory muscles $[12,13]$.

\section{Treatment with myobrace appliance}

Myobrace ${ }^{\circledR}$ devices are a three-phase device system designed to correct bad oral habits when treating jaw development problems. They aim to correctly position the tongue in the upper jaw, re-educate the oral musculature and exert force to align the teeth [14]. It is most effective in primary dentition from the age of three.

In phase $1, \mathrm{~J} 1$ promotes a correction of habits and adapts easily because it is made of flexible silicone. It has anterior and posterior air mattresses that improve muscle function in children in primary dentition. J2 offers the development of the dental arch and the correction of habits. It consists of a medium hard material that helps in the enlargement and development of the jaws. The J3 offers continuous jaw development and occlusal correction. The material it uses is hard polyurethane, which allows excellent alignment of the teeth (Figure 1). The extended tongue positioner completes the correction of the tongue position $[15,16]$.

\section{Myobrace for kids ${ }^{\mathrm{TM}}$}

It is a system of three-phase devices designed to correct bad oral habits when treating jaw development problems. It is more effective after the permanent front teeth have erupted and before the eruption of the other permanent teeth [16]. K1 = it promotes the correction of habits and is made of flexible silicone for easy adaptation to any form of dental arch and malocclusion. It offers great retention due to its material to be used at night. $\mathrm{K} 2$ = it provides dental arch development and correction of habits. It has Dynamicore with Frankel grid that helps in the enlargement and development of the jaw. It is ideal
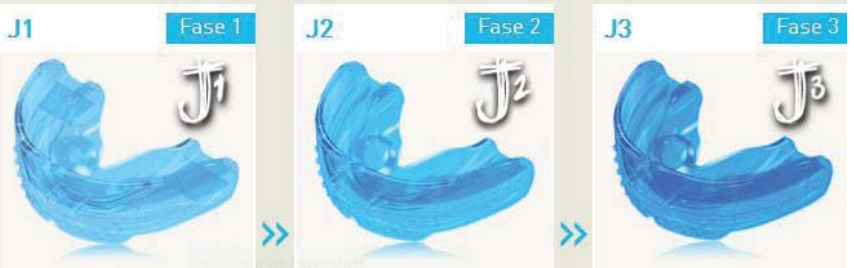

Figure 1: Myobrace for primary dentition and the three phases SourceM,NJ,F: MYOFUNCTIONAL RESEARCH CO., 2016).

Citation: Cunha Busquet PD, Jesus Portelinha DD, Da Costa ML, Cancio de Paula VDA (2021) How the myobrace appliance works: Advantages and disadvantages 
for children aged between 5 and 10 years. $\mathrm{K} 3=$ it concentrates on completing the correction of the habit, the final alignment of the teeth and the retention with its firmer polyurethane construction. The hollow tongue positioner facilitates the final position of the tongue directly in the correct location. It also acts as a retainer until the permanent dentition erupts. $\mathrm{K} 3$ can be combined with the transition to $\mathrm{T} 3$ and $\mathrm{T} 4$ for final dental alignment in developing permanent dentition (Figure 2) $[17,18]$.

Pompeia, et al. [17] presented a clinical case in which the patient had an $8 \mathrm{~mm}$ anterior open dental bite and a posterior cross bite on the right side, due to moderate maxillary atresia, as well as moderate midline deviation. On functional examination, tongue interposition was observed during rest and phonation, atypical swallowing and poor head posture. The treatment plan was to use sequences of Myobrace ${ }^{\circledR}$ devices, starting with occlusal adjustment in the posterior battery and direct flat tracks in the primary molars, concomitant with the use of the Myobrace ${ }^{\circledR}$ K1 soft to correct habits. For all devices in the system, it was recommended to use 1-2 hours during the day and another 10-12 hours during sleep. Analyzing the dental arch, correction of the anterior open bite was observed, with unraveling of the bite and Class II correction on the left side and midline. A slight overjet of element 11 and mesialization of 13 were also noted, both with correction planning with fixed orthodontics, only for small alignment corrections. The head exam showed rectification of the profile, improvement in the nasolabial angle and improvement in the muscular activity of the craniofacial system. The asymmetry has been smoothed out, but it still persists, possibly due to muscle discrepancy due to growth while the bite was crossed.

\section{Myobrace for teens ${ }^{\mathrm{TM}}$ [15]}

It is a four-stage system designed to replace the need for complex orthodontics with brackets and extractions. Its main function is to correct mouth breathing and the incorrect myofunctional habits that cause malocclusion, while the stage 3 device ( $\mathrm{T} 3$ ) guides permanent teeth to break into their natural and correct alignment in the developing dentition stage. When compliance is good, brackets are usually not needed. Daytime use is for an hour, and at night the use is during sleep. It was designed to treat malocclusion in late mixed dentition, Class II Division 1 and 2 malocclusion, anterior crowding (upper and lower), deep bite and open bite [15].

$\mathrm{T} 1$ is aimed at establishing breathing through the nose and correcting myofunctional habits. It is soft and flexible, providing the best adaptation, adapting to any form of dental arch and malocclusion and optimizing the permanence in the position during the night. The transition to $\mathrm{T} 2$ happens only when $\mathrm{T} 1$ remains in the mouth throughout the night and breathing through the nose is established. T2 focuses on obtaining and maintaining the correct dental arch development with Dynamicore ${ }^{\mathrm{TM}}$ specific for this age group, which has extra elements in the anterior region to promote the extra development of the anterior dental arch shape. This provides space for the tongue to establish the correct resting position and swallowing patterns, which improves tooth alignment [15].
T3 is the dental alignment stage of the treatment, with Dynamicore $^{\mathrm{TM}}$ acting as a wire and the dental slots increased the dental arch length, along with auxiliary dental alignment. Compliance with $\mathrm{T} 3$ is essential to avoid loss of space in the arch, which occurs when the device is not used regularly. T3 is predominantly concentrated in dental alignment, but it still presents characteristics of correcting habits similar to those of $\mathrm{T} 1$ and $\mathrm{T} 2$. The $\mathrm{T} 4$ is the final appliance in the Teens series, which maintains all corrections of habits, maintains dental alignment and reinforces good lip posture and breathing through the nose. $\mathrm{T} 4$ focuses on the final alignment of teeth and jaws and is used as a retainer when treatment is complete. The hollow tongue positioner encourages the tongue to position itself in the correct location. It can be used as a longterm retainer (Figure 3) [15].

\section{Myobrace for adults ${ }^{\mathrm{TM}}$}

It is a three-stage appliance system for permanent dentition. For the adult patient, all growth has already occurred and the teeth are in their most stable position. Mouth breathing and incorrect swallowing habits have been established over many years and are more difficult to correct. For these reasons, results in adults are not as predictable as it is in children. The Myobrace ${ }^{\circledR}$ appliance series for adults incorporates the same features as MRC's proven appliance design principles. It can also be used with the Farrell Bent Wire System. This appliance line was designed to treat most malocclusions in adult patients, anterior crowding of mild to medium intensity, as well as lower and upper crowding, and as a treatment of anterior alignment

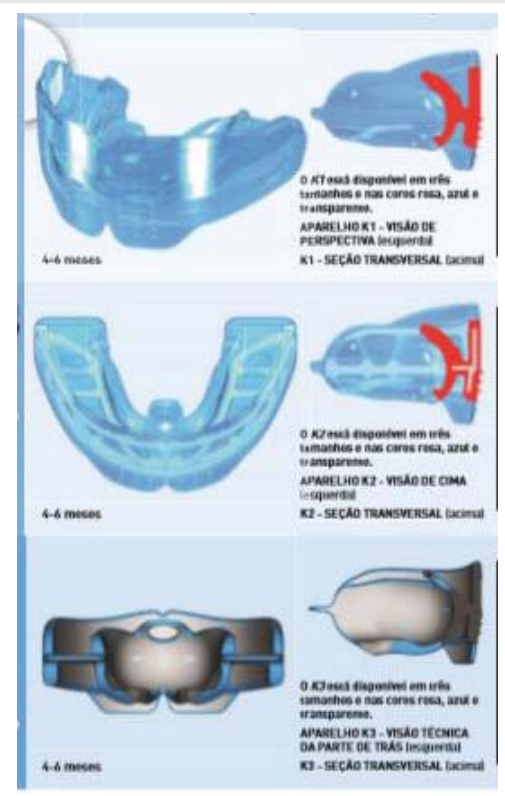

Figure 2: Stages of Myobrace Kids Source: Myobrace Catalog, 2019

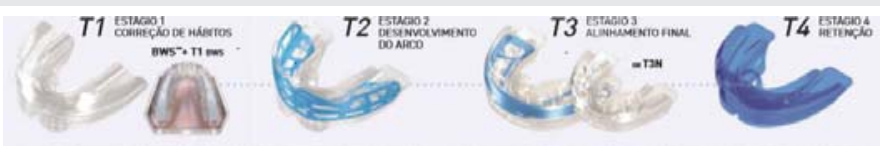

Figure 3: Sequence of Myobrace ${ }^{\circledR}$ Devices for Teens Source: MRC, 2019 
recurrence after orthodontic treatment with brackets, Class II Moderate - Division 1 and Division 2 [4].

In a clinical case published in the literature [18], deep bite, Class II Angle relationship was observed in canines and molars, tooth 44 in relation to Brodie, low tongue, deep palate and dry mucous membranes. A McNamara cephalometric analysis showed a deficiency in the growth of the maxilla and a change in the size of the upper and lower airways. Panoramic radiographs and lateral teleradiography showed the patient's initial situation. The interpretation of these values confirmed the hypothesis of a diagnosis of mouth breathing. The treatment plan was the large Myobrace A2 (Miofunctional Investigation CO - Australia) for having characteristics compatible with the treatment objective. In this case, in parallel with the work of speech therapy, the patient was instructed to perform exercises to reposition the tongue on the palate, strengthen the orbicularis oris muscle, relax the mentalis muscle, among others. Therefore, a change in the profile was observed through mandibular advancement. The balance in the musculature enabled the correct intercuspation and the regularization of breathing.

Myobrace myofunctional devices are advantageous because they are different from other types of Trainers, they are equipped with an additional internal rigid element (dynamicore) that makes the jaw and jaw shields more resistant and consequently increases the ability to neutralize the force generated in the teeth muscles by buccinators and Orbicular muscles, when they are hyperactive. They also provide moderate expansion and correction of the dental arch shape. They exerts a muscular strength in the teeth and they have a high elastic memory. Their preformed shape produces elongation and correction of the shape of the dental arch at the front. Myobrace is designed to combine the dental alignment capabilities of rigid braces and smooth, flexible properties $[6,8]$. Myobrace $^{\mathrm{TM}}$ has greater patient cooperation because of its two-material technology, and after it is removed, the tongue and lips can continue alignment due to Myobrace ${ }^{\mathrm{TM}}$ unique myofunctional reeducation features [15]. Disadvantages for using Myobrace devices have not been described in the literature [8].

\section{Discussion}

Based on the selected studies, mouth breathing associated with low tongue position interferes with tooth positioning and face development. Through orthodontic mechanics, the patient gets more quality of life, making him breathe better, chew better and have facial harmony. In his study, a profile change occurred with mandibular advancement and intercuspation was naturally achieved through muscle balance and regularization of breathing [11].

There are several aspects that are altered in patients with mouth breathing. It can be highlighted, among them alteration of the facial profile, occlusal changes such as anterior open bite, marked overjet (overjet), changes in bite (overbit) and changes in incisor inclination, changes in stomatognathic functions, deleterious habits, among others. When breathing is performed through the mouth, it brings a series of bone and muscle changes especially during the growth phase.
Regarding malocclusions, it is important to identify the factors and conditions associated with them, enabling the construction of models to understand their occurrence, where they are associated with prolonged sucking habits [10]. The more serious the problem, the greater the functional and psychological impact of malocclusion, the child can become the object of bullying which can cause behavioral disorders [18].

Myofunctional orthodontics is gaining more and more importance and visibility in Dentistry, due to the advantages it provides to treatments and the benefits it generates for the general health of patients [19].

Pompeia, et al. [17] concluded that the trainer system, type Myobrace Kids and Junior can be an excellent tool in the treatment of malocclusions in growing patients, especially when the objective is to correct habits and posture that interfere in the balance of the NMS, but it also showed effective for bone and dental corrections, as well as any other functional orthopedic appliance.

Myobrace ${ }^{\mathrm{TM}}$ can be used at any age, in mixed or permanent dentition. The ideal age is during eruptive and growth changes in the final stage of mixed dentition. The longer the permanent dentition is installed, the less effective Myobrace ${ }^{\mathrm{TM}}$ will be. However, factors such as cooperation, degree of myofunctional correction and malocclusion have their influence.

There is little literature available on Myobrace, so there may be flaws in the evaluation of the articles that were included in this review. New studies must be carried out in order to fill these gaps.

\section{Conclusion}

Considering our literature review, this tool is effective in treating malocclusion in mixed dentition, especially for low-income patients, as it represents a considerably cheaper technique when compared to other orthopedic treatments.

\section{References}

1. Saccomanno S, Antonini G, D'Alatri L, D'Angelantonio M, Fiorita A, et al. (2012) Patients treated with orthodontic-myofunctional therapeutic protocol. Eur J Paediatr Dent. 13: 241-243. Link: http://bit.ly/3tKhQtl

2. Rogers AP (1939) Evolution, development, and application of myofunctional therapy in orthodontics. Am J Orthod Oral Surg. 25: 1-19. Link: http://bit.ly/3qYFMac

3. Thompson JR (1962) Abnormal function of the stomatognathic system and its orthodontic implications. Am J Orthod Dentofacial Orthop. 48: 758-765. Link: Link: http://bit.ly/2Nsesnc

4. Lemos CM, Junqueira PAS, Gomez VSGG, Faria MEJ, Basso SC (2006) Estudo da relação entre a oclusão dentária e a deglutição no respirador oral. Arq Int Otorrinolaringol. 10: 114-118. Link: https://bit.ly/3bXyKi0

5. Melchior MDO, Magri LV, Mazzetto MO (2018) Orofacial myofunctional disorder, a possible complicating factor in the management of painful temporomandibular disorder. Case report. BrJP. 1: 80-86. Link: http://bit.ly/3s2eic3

6. Anastasi G, Dinnella A (2014) Myobrace System: A no-braces approach to malocclusion and a myofunctional therapy device. Webmed Central Orthodontics. 5: WMC004492. 004492. Link: http://bit.ly/3bWPeH1 
7. Janson G, Garib DG, Pinzan A, Henriques JFC, Freitas MR de (2013) Introdução à ortodontia. $1^{\mathrm{a} e d}$ ed Brasil: São Paulo.

8. Tomita NE, Bijella VT, Franco LJ (2000) Relação entre hábitos bucais e má oclusão em pré-escolares. Rev. Saúde. 34: 299-303. Link: http://bit.ly/38NsCH5

9. Felício CM de, Trawitzki LVV, Marques AP, Fernandes FDM, Ferreira VJA (2009) Interfaces da medicina, odontologia e fonoaudiologia no complexo cérvico-craniofacial. $1^{\mathrm{a}}$ ed. Brasil: São Paulo.

10. Menezes VA, Cavalcanti LL, Albuquerque TC, Garcia AFG, Leal RB (2011) Respiração bucal no contexto multidisciplinar: percepção de ortodontistas da cidade do Recife. Dental Press J Orthod. 16: 84-92. Link: https://bit.ly/2QbRvFL

11. Macho V, Andrade D, Areias C, Norton A, Coelho A, et al. (2012) Prevalence of deleterious oral habits and occlusal anomalies in a population aged 3-13 years. Rev Port Estomatol Med Dent Cir Maxilofac. 53: 143-147. Link: http://bit.ly/38V2sSS

12. Cavassani VGS, Ribero SG, Nemr NK, Greco AM (2003) Hábitos orais de sucção: estudo piloto em população de baixa renda. Rev Bras Otorrinolaringol. 69: 106-110. Link: http://bit.ly/3vBxkBk
13. Sociedade de Pediatria de São Paulo (2011) Hábitos de Sucção da criança Recomendações: Atualizações de Conduta em Pediatria. 57: 12-14.

14. Fernandes LFT, Kochenborger R, Woitchunas FE, Woitchunas DR (2010) A influência da deglutição atípica no padrão craniofacial e na morfologia mandibular. RFO UPF. 15. Link: http://bit.ly/38S9ilu

15. Myofunctional Research CO (2020) Myobrace para crianças pequenas dentição decídua.

16. Queluz DDP, Gimenez CMM (2000) A síndrome do respirador bucal. Rev. CROMG (Impr.). 2000 Jan-Abr 4-9.

17. Pompeia LE, Rossetti RM, Faria PR, Ortolani CLF, Faltin Jr K (2017) Tratamento de mordida aberta anterior com terapia miofuncional - relato de caso. Orthod Sci Pract. 10: 75-81. Link: http://bit.ly/38RXPc8

18. Faria PR (2014) The use of Myofunctional Orthodontics in the treatment of children and teenagers. Ortho Sci Orthod sci pract. 7: 401-406. Link: https://bit.ly/3eQhooY

19. Levrini L, Salone GS, Ramirez-Yanez GO (2018) Pre-Fabricated Myofunctional Appliance for the Treatment of Mild to Moderate Pediatric Obstructive Sleep Apnea: A Preliminary Report. J Clin Pediatr Dent. 42: 236-239. Link: http://bit.ly/3r00vsy

\section{Discover a bigger Impact and Visibility of your article publication with}

\section{Peertechz Publications}

\section{Highlights}

* Signatory publisher of ORCID

* Signatory Publisher of DORA (San Francisco Declaration on Research Assessment)

- Articles archived in worlds' renowned service providers such as Portico, CNKI, AGRIS, TDNet, Base (Bielefeld University Library), CrossRef, Scilit, J-Gate etc.

* Journals indexed in ICMJE, SHERPA/ROMEO, Google Scholar etc.

- OAI-PMH (Open Archives Initiative Protocol for Metadata Harvesting)

* Dedicated Editorial Board for every journal

* Accurate and rapid peer-review process

* Increased citations of published articles through promotions

* Reduced timeline for article publication

Submit your articles and experience a new surge in publication services (https://www.peertechz.com/submission).

Peertechz journals wishes everlasting success in your every endeavours.

Copyright: ๑ 2021 Cunha Busquet PD, et al. This is an open-access article distributed under the terms of the Creative Commons Attribution License, which permits unrestricted use, distribution, and reproduction in any medium, provided the original author and source are credited. 